\title{
LOS FRUTALES DEL NORDESTE ARGENTINO EN LA "MATERIA MÉDICA MISIONERA" DEL JESUITA PEDRO MONTENEGRO
}

\author{
The fruits of the Argentine Northeast in the "Materia Medica Misionera" publication by Jesuit \\ Pedro Montenegro
}

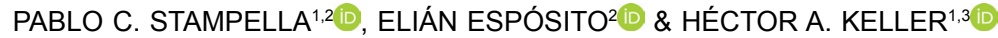

\begin{abstract}
Resumen: Los misioneros jesuitas (siglos XVII-XVIII) no sólo cumplieron un rol importantísimo en la introducción de plantas exóticas de diversos enclaves del mundo, sino también en la circulación de saberes, medicamentos y prácticas curativas entre las misiones del Paraguay con las del resto del Nuevo y Viejo Mundo. Sin embargo, los trabajos científicos que abordan la identificación de estas plantas, tanto nativas como introducidas, son escasos y dispersos. EI objetivo de la presente contribución fue identificar los frutales locales citados en la publicación "Materia Médica Misionera" de 2009 por el jesuita Pedro de Montenegro, como también discutir algunos aspectos relacionados a las dificultades de esta tarea de identificación. La metodología empleada fue la perteneciente a la etnobotánica histórica. A partir de la obra del jesuita Pedro Montenegro, se identificaron los frutales locales empleando las descripciones y láminas acompañantes del autor, y comparándolas con bibliografía científica. Se identificaron 12 etnogéneros y 31 etnoespecies pertenecientes a las familias botánicas Arecaceae, Bromeliaceae, Caricaceae, Fabaceae, Myrtaceae, Musaceae y Passifloraceae.
\end{abstract}

Palabras clave: Etnobotánica histórica, frutales, jesuitas, Materia Médica, Misiones, Montenegro.

Summary: Jesuit missionaries (17-18th centuries) not only played a very important role in the introduction of exotic plants from various places of the world, but also in the dissemination of knowledge, medicine and healing practices among the missions in Paraguay and in the rest of the New and Old World. However, the scientific research dealing with the identification of these plants, both native and introduced, is scarce and scattered. The goal of this study was to identify local fruit trees cited in the "Materia Medica Misionera" publication from 2009 by Jesuit Pedro de Montenegro of the mentioned work, as well as to discuss some aspects related to the difficulties of this identification task. The methodology used was historical ethnobotany. Starting with Montenegros' work, local fruit trees were identified using descriptions and accompanying sheets of the author that were compared with the scientific literature. Twelve ethnogenera and thirty one ethnospecies belonging to the botanical families Arecaceae, Bromeliaceae, Caricaceae, Fabaceae, Myrtaceae, Musaceae, and Passifloraceae, were identified.

Key words: Fruit plants, Historical ethnobotany, Jesuits, Medical Matter, Misiones, Montenegro.

\section{Introducción}

Los misioneros jesuitas de los siglos XVII y XVIII cumplieron un rol importantísimo tanto en la introducción de plantas exóticas de diversas partes del mundo, como en la circulación de saberes, medicamentos y prácticas curativas entre las misiones de Paracuaria (provincia jesuítica del Paraguay) y otras del Nuevo y del Viejo Mundo (Deckmann Fleck, 2013; Stampella et al., 2013; Hilgert et al., 2014; Poletto, 2014).

\footnotetext{
${ }^{1}$ Investigador CONICET

${ }^{2}$ Laboratorio de Etnobotánica y Botánica Aplicada (LEBA, FCNyM, UNLP). E-mail: stampellapablo@gmail.com

${ }^{3}$ Instituto de Botánica del Nordeste (IBONE). E-mail: kellerhector@hotmail.com
} 
En lo que respecta a las plantas nativas, esa interacción estuvo matizada por analogías con las plantas útiles europeas, en especial con las mencionadas en las obras de Dioscorides, Mattioli, Laguna, Plinio, Monardes y Pisón, entre otros (Montenegro, 2009). Así, son comunes las descripciones de las plantas nativas por comparación con las originarias de los lugares de donde provenían los jesuitas: comparación de las mirtáceas frutales como el "guabirá", Campomanesia xanthocarpa (Mart.) O. Berg y el "guabiyú" o "arrayán", Myrcianthes pungens (O. Berg) D. Legrand, con rosáceas como peras, ciruelas y cerezas; de los "aguarandios" locales, Piper regnelli (Miq.) C. DC., P. aduncum L. y otras, con el "asaro" de Dioscorides; y del "caané", Dysphania ambrosioides (L.) Mosyakin \& Clemants, con el "lepidio" de Plinio (Dobrizhoffer, 1967; Montenegro, 2009). También las transposiciones de conocimientos fueron realizadas directamente, como en el caso del "ricino", Ricinus communis L.: puede compararse la descripción del jesuita Pedro Montenegro en su obra Materia Médica Misionera de 1710 (Montenegro, 2009: 293-294) con la de Andrés Laguna, médico español del siglo XVI, resultando casi idénticas (Keller et al., 2018).

Los primeros trabajos relacionados con la identificación de plantas fueron las traducciones y análisis de las obras de los misioneros jesuitas Sepp, Paucke, Dobrizhoffer y Sánchez Labrador, llevadas a cabo por Werner Hoffmann, Edmundo Wernicke, Guillermo Furlong, Ernesto Maeder y Héctor Sainz, entre otros (Paucke, 1944; Dobrizhoffer, 1967; Sepp, 1971; Sainz et al., 1989). En los últimos años se han incrementado los trabajos etnobotánicos históricos que analizan obras de padres misioneros jesuitas de los siglos XVII y XVIII. Estos trabajos revelan la importancia de las fuentes documentales, por ejemplo, para el estudio etnobotánico de comunidades nativas (Arenas, 1997), para el análisis de la construcción del paisaje como proceso histórico (Capparelli et al., 2011; Stampella et al., 2013; Hilgert et al., 2014; Stampella, 2015), para la interpretación de los cambios en el uso de las plantas con órganos de almacenamiento subterráneos a través del tiempo (Ochoa \& Ladio, 2011), como también de los usos de las plantas en general, antes y después del contacto con los misioneros jesuitas (Rosso,
2012, 2013). Sin embargo, entre estos trabajos son escasos los que identifican la afiliación botánica de las especies involucradas. Arenas (1997) destaca que han sido identificadas casi la totalidad de las plantas mencionadas en la obra de Martín Dobrizhoffer (1967). Sin embargo, esos resultados no han sido publicados. Más recientemente, Rosso (2012) identificó el 60\% de las plantas de la obra de Florián Paucke (1944), porcentaje que asciende a $74 \%$ si se tienen en cuenta algunas etnoespecies de identificación botánica tentativa.

Otros trabajos previos también tratan aspectos parciales de la Materia Médica Misionera. Algunos de ellos no identifican las plantas sino que analizan determinados aspectos de la obra como la vida del autor, la teoría hipocrático-galénica, los saberes nativos y las resignificaciones (Poletto, 2014), la medicina herbolaria relacionada a las enfermedades mentales (Ibarra, 2007), la identificación de algunas plantas empleadas en el tratamiento contra el veneno de ofidios (Ricciardi et al., 1996), o las plantas autóctonas componentes de las drogas encontradas en la botica jesuítica de la ciudad de Santa María de los Buenos Ayres (Perkins de Piacentino, 2007).

A pesar de estas cuestiones, la obra de Pedro Montenegro ha trascendido los tiempos, habiendo sido incluso publicada recientemente por la Universidad de Misiones y por diversas editoriales. Así, es evidente la vacancia en las identificaciones botánicas de las obras de los jesuitas, debido a que muy pocas de ellas poseen descripciones detalladas e ilustraciones de las mismas. Entre las pocas que pueden mencionarse figuran las de los padres Florian Paucke, Martín Dobrizhoffer, José Sánchez Labrador y Gaspar Juárez, todos ellos jesuitas pertenecientes al último período de las misiones (hacia mediados del siglo XVIII).

El objetivo de este trabajo es la identificación botánica de las especies frutales locales de la obra de Montenegro, y discutir algunos aspectos relacionados a las dificultades de la tarea de identificación.

\section{Materiales y Métodos}

La fuente seleccionada fue "Materia Médica Misionera" de Pedro Montenegro [1710]. Este nombre fue dado al manuscrito, depositado 
en la Biblioteca Nacional, por Ricardo Trelles (Martínezetal., 1990:345).PedrodeMontenegro nació en España en 1663 y murió en 1728 en la reducción de Mártires (Misiones, Argentina), cerca de la zona donde ejerció la medicina desde fines del siglo XVII. En esta obra Montenegro describió cerca de 150 plantas mayormente nativas, aportando información etnomédica y de su propia experiencia (preparaciones, formas de administración y efectos) como también ilustraciones provenientes de la "Historia Naturalis Brasiliae" de W. Piso (año 1648) (Anagnostou, 2005).

Para el abordaje de esta obra se empleó la metodología etnobotánica histórica, consistente en el análisis antropológico diacrónico de fuentes históricas con el objetivo de indagar en la relación entre las comunidades locales y su entorno vegetal (Trinidade Medeiros, 2010a, b). Los frutales seleccionados de Materia Médica Misionera fueron tratados como etnoespecies, entendidas en el sentido de Rosso (2013: 58): "especies locales mencionadas en las fuentes históricas citadas generalmente con un nombre vernáculo". De la misma manera se hizo extensiva la referencia a etnogénero.

A partir de la lectura de la obra, se relevaron los frutales nativos de la obra y se identificaron a partir de las descripciones y láminas acompañantes. Se emplearon trabajos generales botánicos y etnobotánicos de referencia (León, 1987; Zuloaga et al., 2008; Kinupp \& Lorenzi, 2014), y también trabajos específicos de familias botánicas como Myrtaceae (Rotman, 1976a, b, 2000; Landrum \& Kawasaki, 1997; Barion Romagnolo \& Conceição de Souza, 2004) y Passifloraceae (Deginani, 2001). Los nombres científicos fueron actualizados según The Plant List (2013).

Como apoyo lingüístico para la identificación botánica se emplearon los trabajos de Storni (1944), Martínez-Crovetto (1981, 2012), Rodríguez Barboza (1985) y Cadogan (1992). Sobre la base de los nombres guaraníes de uso corriente en la actualidad, la interpretación de ciertos rasgos morfológicos mencionados en el texto, las imágenes presentes en el mismo y la utilización de bibliografía especializada, se ha podido identificar la ubicación taxonómica actual de ciertas especies presentes en la Materia Médica Misionera de Montenegro (2009).

\section{Resultados y Discusión}

La identificación botánica de las plantas de la obra en estudio presentó diferentes niveles de complejidad. Por un lado, algunas de las descripciones de las especies y variedades son escuetas e incompletas, por ejemplo, la del "arrayán montano negro" o "guabiyú" (Myrcianthes pungens), que fue identificado exclusivamente por su característica espina en el ápice foliar. Por otra parte, la transposición de descripciones de plantas exóticas por parte de autores clásicos hacia las plantas nativas, constituyó otro problema para la identificación botánica, aunque de alguna manera fue de utilidad para la complementación de las descripciones escuetas. La diferenciación entre variedades "masculinas" y "femeninas", "blancas" y “negras", "mayor" (guazú) y "menor" (miní), aún vigente en la etnotaxonomía guaraní (Martínez-Crovetto, 2012), ha sido otro aspecto común de la obra de Montenegro y de la época, que aumentó la complejidad de las identificaciones. A veces, estas diferenciaciones se corresponden con variedades de la misma especie o con especies afines. En otros casos, un mismo nombre vernáculo se refiere a especies no emparentadas. Las descripciones de las "especies de arrayanes montanos" (Myrcianthes, Plinia) y "algarrobos" (Prosopis) ejemplifican ese primer aspecto, mientras que los tipos de "nueces purgantes" (Ricinus, Cascabela, entre otras) ejemplifican el segundo (Keller et al., 2018).

Se identificaron 12 etnogéneros, con 31 etnoespecies. Los etnogéneros y etnoespecies identificados se ubican en las familias botánicas Myrtaceae (4 etnogéneros y 12 etnoespecies), Fabaceae (3 etnogéneros y 8 etnoespecies), Arecaceae (1 etnogénero y 1 etnoespecie), Bromeliaceae (1 etnogénero y 2 etnoespecies), Caricaceae (1 etnogénero y 2 etnoespecies), Musaceae (1 etnogénero y 2 etnoespecies) y Passifloraceae (1 etnogénero y 4 etnoespecies).

A continuación se presentan las especies frutales identificadas, agrupadas por orden de aparición en la obra, indicando, en caso de presentarse, las siguientes asignaciones: nombre español (esp), nombre guaraní (guar), nombres científicos y familia botánica. Seguidamente se transcribieron los fragmentos 
de la obra, según se encuentran en ella, que han sido empleados para la identificación, indicando también la página del libro en la que se encuentran. Posteriormente, para cada caso, se discutió sobre la identificación botánica respectiva y los usos presentados por Montenegro en relación a los actuales.

1. "Arrayán silvestre negro", "guabiyú grande negro" (esp). "Guabiyú", "guabiyú guazú” (guar). Myrcianthes pungens (O. Berg) D. Legrand. MYRTACEAE (Fig. 1a, b).

Según Montenegro, este frutal: "Nace por los montes, arroyos, y por las campañas á donde hay minas de piedra, ó por los Cerros de Cerranías, como San Xavier, y Sta. Maria”. El guabiyú es arbol de mediano grosor y grandor; pero muy solido y fuerte, y incorruptible (...). [El] Guabiyú grande negro (...) tiene la oja gruesa con espina en la punta" (p. 89).

La asociación a afloramientos rocosos, el porte de la planta y la característica espina en el ápice de la lámina foliar son propias de Myrcianthes pungens. "Guabiyú", en guaraní, significa "fruto con vello" (Storni, 1944) y es actualmente empleado por campesinos y guaraníes de la provincia de Misiones y países limítrofes como medicinal (estimulante, estomacal, febrífugo y diurético), como leña y como frutal, especialmente por los niños (Keller, 2008b; Carrere, 2009; Martínez-Crovetto, 2012; Stampella, 2015).

El autor cita otros usos como tintóreo (tiñe de negro) y maderero, para torneros y estatuas pequeñas. Como medicinal también menciona que se emplea como antidiarreico y en disenterías. Dobrizhoffer (1967) la denomina "Quabiyú" e indica el valor de sus frutos como comestibles y para preparar bebidas, además, como remedio estomacal.

2. “Arrayán montano negro menor" (esp). "Ibauh", "guabiyú mirí" (guar). Myrcianthes gigantea (D. Legrand) D. Legrand (?), Plinia rivularis (Cambess.) Rotman (?), Eugenia psidiiflora $\mathrm{O}$. Berg (=Calycorectes psidiiflorus (O. Berg) Sobral) (?). MYRTACEAE.

(...) "nace muy de ordinario á las orillas de los arroyos en partes humedas pedregosas, y asi mismo á las orillas de los montes en partes bajas y humedas con abundancia: su corteza es terza y blanquecina muy semejante al mayor, y sin espina en la punta, y asi mismo mas humedas al tacto, y mas lisas: sus flores son blanquecinas tirante un poco al color amarillo, y muchas juntas á modo de racimo, ó pomo: su fruto es asi mismo negricante al sazonar; pero mucho menor que el Guabiyú guazú" (p. 92).

Esta somera descripción no permite concluir fehacientemente de qué especie se trata, pero sí se puede mencionar que el jesuita se refiere a una especie de la familia Myrtaceae similar a Myrcianthes pungens. Quizás se trate de Plinia rivularis, abundante en la zona, con frutos más pequeños en racimos, o Myrcianthes gigantea, de características similares a $M$. pungens pero con frutos también en racimos.

El jesuita menciona que posee las mismas propiedades que el "guabiyú" pero que, además, era empleado en casos de contusiones, fracturas y dislocaciones de huesos, y para "flujos de vientre". Este arbolito constituye en la actualidad un frutal importante para los guaraníes y criollos, siendo empleado fundamentalmente como comestible y medicinal (Keller, 2008a; Stampella, 2015).

3. “Arrayán blanco montano" (esp). "Añangapiri guazú" y "añangapiri mirí” (guar). Eugenia uniflora L., Eugenia pitanga (O. Berg) Nied. y Eugenia pyriformis Cambess. var. uvalha (Cambess.) D. Legrand (?). MYRTACEAE (Fig. 2).

(...) es un arbolito muy pequeño, su fruto del tamaño de una cereza garrafal, y á veces mayor (...), que por los bosques y arroyos hay cantidad de arboles mayores, que llama el Indio Añangapiri mirí, porque su fruto es muy pequeño, aunque el arbol es grande. Tiene el Añangapiri guazú dos especies: uno crece como una vara y media de alto (ca. 1,27 m), y el otro como una tercia (ca. $30 \mathrm{~cm}$ ), y de ordinario en tierras sobre canteras de piedra, ó cascajosa. (...) La frutilla del Añangapiri es mas sabrosa $y$ de mejor olor que la del Guabiyú: de color anaranjado tirante á colorado, con ciertas rayas, ó endeduras, á modo de las conchas, consta de uno ó dos huesos y tiene su coronilla á modo de la del Guabiyú" (p. 96).

Esta descripción es bastante detallada con respecto al porte, hábitat y fruto, con la cual, no quedan dudas de que el "añangapiri mirí" corresponde a Eugenia uniflora. Al respecto, 


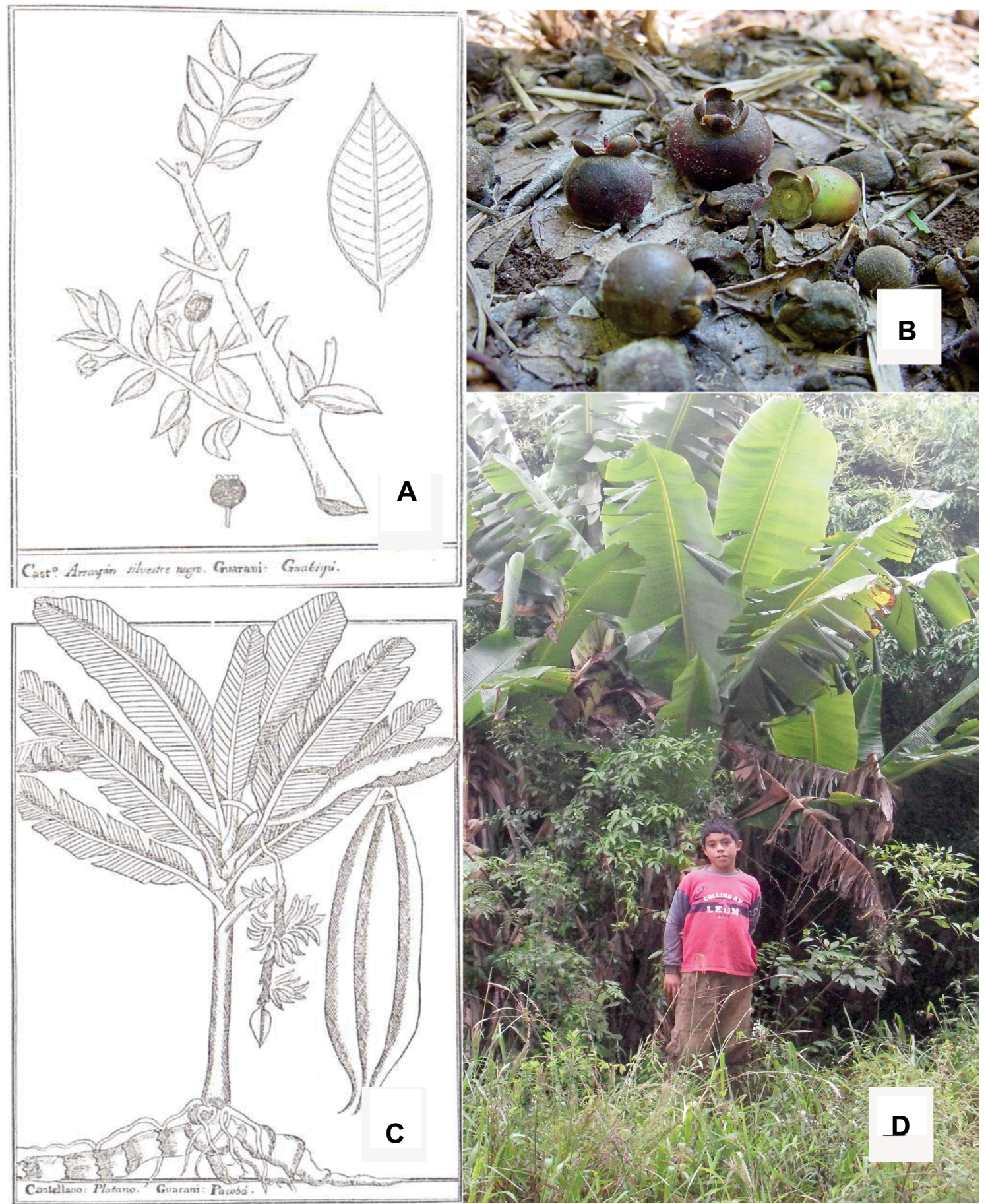

Fig. 1. "Guabiyú" (Myrcianthes pungens) y "Pacobá" o "plátano" (Musa paradisiaca). A: Esquema de la planta de "guabiyúu". B: Detalle de los frutos de "guabiyú". C: Esquema de la planta de "plátano" con detalle de sus frutos. D: Aspecto de un ejemplar de "plátano". Créditos: A, C, Tomado de Montenegro; B, Foto H. Keller; D, Foto P. Stampella. Fig. 1. "Guabiyú" (Myrcianthes pungens) and "Pacobá" or "plátano" (Musa paradisiaca). A: Scheme of the "guabiyú" plant. B: Detail of the "guabiyú" fruits. C: Scheme of the "banana" plant with details of its fruits. D: Aspect of a "banana" specimen. Credits: A, C, Taken from Montenegro; B, Photo H. Keller; D, Photo P. Stampella. 


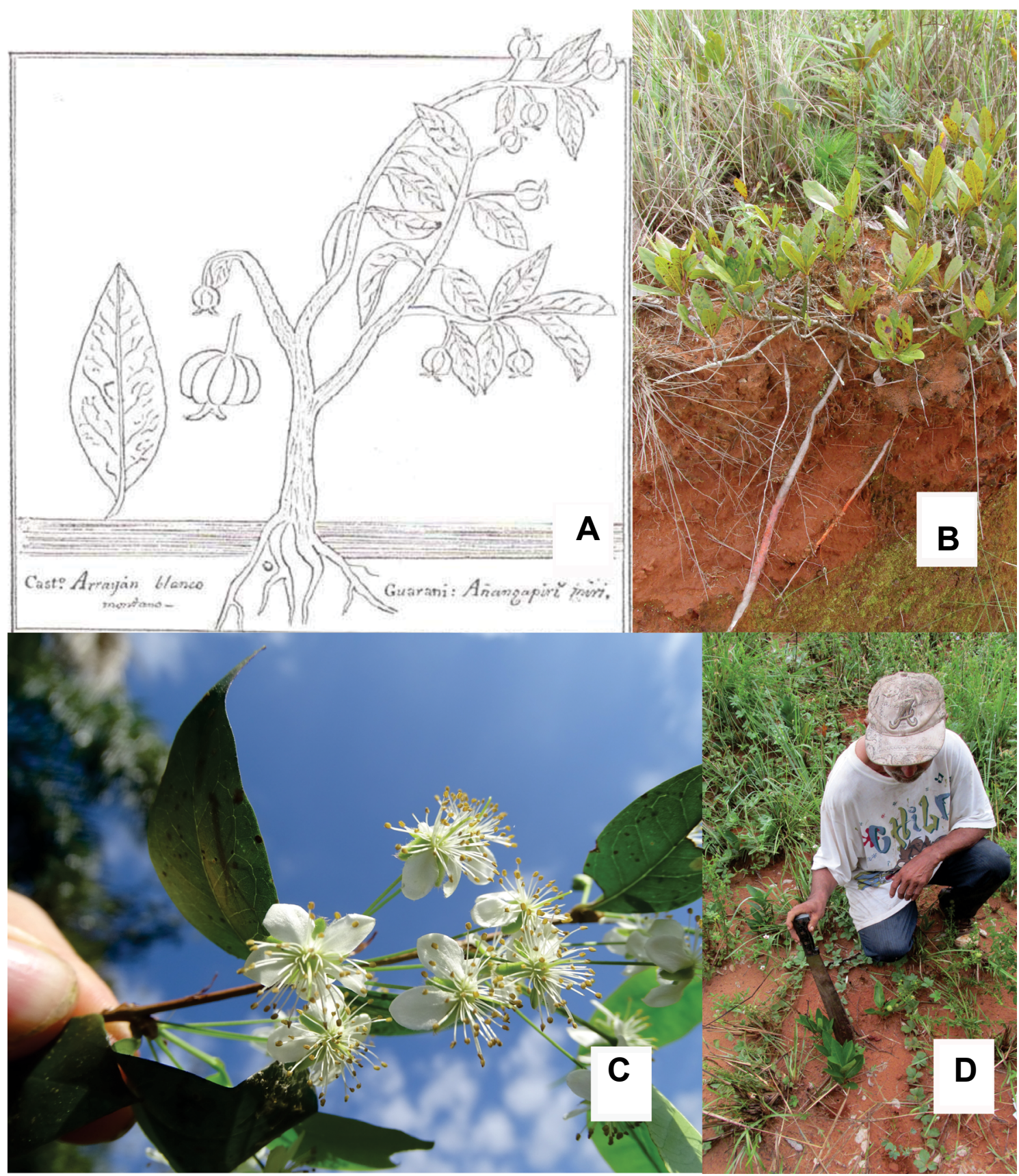

Fig. 2. "Añangapiri”. A: Esquema de la planta de "añangapiri mirí" (Eugenia uniflora). B: Detalle de rama con flores de "añangapiri mirí". C: Ejemplar de "añangapiri guazú" (Eugenia pitanga) con xilopodios a la vista. D: Aspecto de un ejemplar adulto de "añangapiri guazú". Créditos: A. Tomado de Montenegro; B-D. Fotos H. Keller.

Fig. 2. "Añangapiri". A: Scheme of the "añangapiri miri" plant (Eugenia uniflora). B: Detail of branch with flowers of "añangapiri miri". C: Specimen of "añangapiri guazú" (Eugenia pitanga) with xylopodium in sight. D: Aspect of an adult specimen of "añangapiri guazú". Credits: A, Taken from Montenegro; B-D, Photos H. Keller. 
Montenegro se refiere a su fruto destacando las costillas ("rayas" o "endeduras") que posee y la cantidad de semillas ("huesos") como también la similitud con Myrcianthes pungens en relación al cáliz persistente por encima del ovario ínfero ("coronilla"). Por el contrario, como "añangapiri guazú" el autor describe vagamente dos variedades, una de poco más de un metro de altura y otra mucho más pequeña, de sólo 30 centímetros. Posiblemente, la primera de ellas pueda tratarse de Eugenia pyriformis var. uvalha, y la más pequeña $E$. pitanga, un arbusto de porte bajo.

Así, de acuerdo a estos resultados (tanto de los guabiyú como de los añangapiri) se amplía el repertorio de probables especies referidas a estas dos etnoespecies por Perkins de Piacentino (2007), que sólo menciona a Myrcianthes cisplatensis (Cambess.) O. Berg, a las antes mencionadas. Si bien esta especie está presente en la provincia de Corrientes y en el estado de Rio Grande do Sul (ambos enclaves incluidos durante los siglos XVII y XVIII en la provincia Jesuítica de Paracuaria) las descripciones indican la mayor diversidad de especies.

El autor menciona a esta planta como medicinal, para tratar contusiones y hemorragias internas, y también como estomáquico y aperitivo. Sánchez Labrador indica esta planta como frutal (Sainz et al., 1989).

Actualmente, Eugenia uniflora es cultivado como ornamental y sus frutos se consumen como fruta fresca y emplean para la elaboración de diversas conservas, dulces y refrescos. En Corrientes se elabora la "caña de añangapiri”. Los frutos inmaduros se utilizan como encurtidos. Los troncos son empleados para construcciones por los guaraníes. Las hojas se emplean en medicina popular, como remedio astringente, diurético, emenagogo, depurativo, digestivo, para bajar el colesterol, antidiarreico, contra el reumatismo, contra la tos, febrífugo e hipotensor (Martínez-Crovetto, 1981, 2012; Schmeda Hirschmann, 1988; Keller, 2008b; Hurrell et al., 2010).

4. "Guayabas", "Guayabas campesinas", “guayabas grandes” (esp). “Arazá”, “arazá guazú", “arazá mirí”, "arazaîmirí” (guar). Psidium australe Cambess., P. australe Cambess. var. argenteum (O. Berg) Landrum, $P$. guajava L., P. guineense Sw., P. kennedyanum Morong, $P$. misionum D. Legrand, $P$. salutare (Kunth) O. Berg var. mucronatum (Cambess.) Landrum, P. salutare (Kunth) O. Berg var. sericeum (Cambess.) Landrum. MYRTACEAE (Fig. 3a, c, d).

Las "guayabas campesinas": “(...) nacen por las campañas ó campos. La mayor tiene su arbol debajo de tierra, ó por mejor decir su tronco: el cual es grueso como el brazo de un hombre fornido: su largo como tres varas $(2,52$ $\mathrm{m})$, ó dos y media $(2,11 \mathrm{~m}), y$ al fin de ellas esparce sus raices como los otros arbolitos por tierra o greda: sus ramas son de á media vara $(0,42 \mathrm{~cm})$ de largo muy espesas, $y$ al salir de tierra comienzan á florecer, y dár fruto en gran copia: de suerte, que no se vé mas en su nacimiento que un montón de frutillas, que al crecer se ban derribando las unas á las otras, ó pudriendose por no tener lugar tantas en tan corto ambito, como en el de una tercia $(30 \mathrm{~cm})$ mas de cien frutillas apiñadas, y tan apretadas unas con otras, que se hasen camas unas á las otras: las cuales cuando sazonan son del tamaño de un mburucuyá de los morados ó negros" (p. 97).

Las "guayabas o "arazá guazú": "Hallanse por estas Misiones del Paraná y Uruguay cuatro especies de Arazás, unas grandes de fruto y ojas semejantes á la de la estampa, otras menores de ojas y frutos; pero su arbol es mas alto y mayor, como de seis varas $(5,04$ $\mathrm{m})$ de alto: hay otra especie muy semejante á estas; pero silvestre, á las orillas de los montes por las campañas, su fruto algo amarillo por de fuera y encarnado adentro. La cuarta especie es la menor de fruto, también silvestre, llamala el Indio Arazá miri, (...) su arbol es distinto en oja y en figura. (...) La primera su arbol crece á modo de matorral, echando muchas ramas en contorno de su raiz divididas, es redondo su fruto del tamaño de un huevo de gallina grande, ó muy poco piramidal: su flor es pequeña de (...) ojas, y tira á ceniciento claro, de cuatro ojitas (...). La segunda es menor de fruto, del tamaño de peras cermenas (Pyrus sp.), es mas claro de color, tirante á pálido, ó blanco rosado, (...) es menos agria, (...) estas dos son las que de ordinario se hallan en las huertas y chacaras de los Indios. La tercera especie (...) nace por las campañas; su fruto mediano con muchos huesecitos, ó 


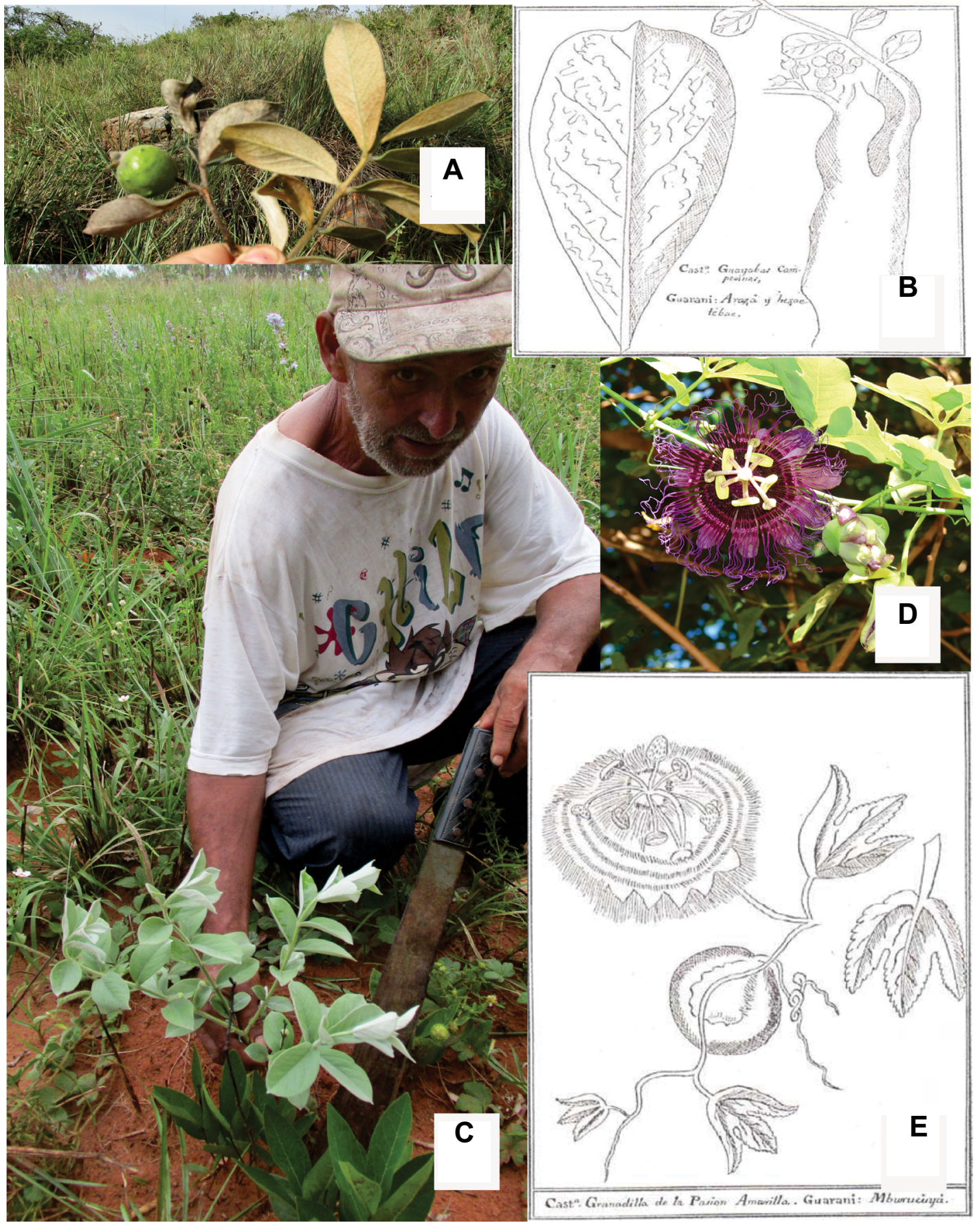

Fig. 3. "Granadilla" o "mburucuyá" (Passiflora cincinnata) y "guayabas campesinas" (Psidium salutare). A: Aspecto de la planta de "guayaba campesina". B: Esquema de las plantas de guayaba campesinas. C: Aspecto de la planta de "guayaba campesina". D: Aspecto de la flor y ramas con hojas de "mburucuyá". E: Esquema de las plantas de "mburucuyá". Créditos: A, C, D, Fotos H. Keller; B, E, Tomados de Montenegro.

Fig. 3. "Granadilla" or "mburucuyá" (Passiflora cincinnata) and "guayabas campesinas" (Psidium salutare). A: Aspect of the "guayaba campesina" plant. B: Outline of "guayaba campesina" plants. C: Aspect of the "guayaba campesina" plant. D: Appearance of the flower and branches with leaves of "mburucuyá". E: Outline of the plants of "mburucuyá". Credits: A, C, D, Photos H. Keller; B, E, Taken from Montenegro. 
pepitas dentro, hay muchas por el Paraná, y Paraguay de esta especie sembradas por las campañas por los animalejos que las comen, $y$ en esta especie hay mayores y menores, aunque cuantidad iguales. La cuarta especie es el Arazaîmiri, en lo cual hay pequeñas de arbol, y mayores que guindas garrafales de fruto, $y$ de arbolito grande, grueso como el brazo de un hombre menor, el fruto mas belloso, sus hojas angostas y largas, asperas y bellosas; (...) y de menos pulpa su fruto. Hallase otra quinta especie muy pequeña de planta, como de media vara $(0,42 \mathrm{~cm})$ crece en alto, muy fertil de fruto, el cual en llegando á sazon se pone algo amarillo: nace por las campañas y en grande abundancia sobre Colonia de San Gabriel (...)" (p. 99-100).

Aquí el autor se ha referido a varias especies del género Psidium, aunque no descartamos la presencia de especies de otros géneros (Campomanesia, por ejemplo), debido a la similitud entre los nombres locales y el porte de las plantas. Con el nombre de "guayabas campesinas" Montenegro alude a $P$. salutare var. sericeum caracterizada por su xilopodio grueso y rizomas hasta de $85 \mathrm{~cm}$, aunque también puede referirse a $P$. salutare var. mucronatum ya que sólo describe a "la mayor". Esta última variedad posiblemente sea la que menciona como "quinta especie (...) en grande abundancia sobre Colonia de San Gabriel (...)", de distribución más amplia y austral (Uruguay y provincias argentinas de Entre Ríos y Buenos Aires). Las primera especie que describe de las "guayabas" o "arazá guazú", que la destaca como silvestre, puede tratarse de $P$. kennedyanum, el "guayabo de monte", de frutos ácidos y amarillos; mientras que la que describe brevemente como "cuarta especie" puede tratarse de $P$. misionum o $P$. australe var. argenteum. Faltarían datos sobre la pubescencia de la planta para saber a cuál de estas especies se refiere el autor. Con la descripción de "la primera" posiblemente se trate de la especie introducida de zonas más ecuatoriales, $P$. guajava, debido a la presencia de frutos redondos y grandes, mientras que con "la segunda" puede estar refiriéndose a $P$. guineense, de frutos menores que P. guajava. El autor menciona que estas dos últimas especies son las que comúnmente se hallan en las "huertas y chacaras de los Indios". Finalmente, con respecto a la "cuarta especie (...), el Arazaîmiri" puede tratarse de $P$. salutare var. mucronatum, debido a su porte bajo y frutos de tamaño similar a Prunus cerasus L. (Rosaceae).

Montenegro recomienda los frutos de las "guayabas campestres" como "único remedio en las flucciones discentericas, y flujos colericos", constituyendo un remedio astringente, antidiarreico. Los frutos y flores del "arazá guazú" son recomendados como remedio estomacal y hepático, para las deposiciones sanguinolentas (camaras de sangre). La mayoría de los textos jesuíticos consultados se refieren a esta diversidad del género Psidium, resaltando su valor como frutal y medicinal, especialmente contra la diarrea (Gilii \& Xuarez, 1792; Dobrizhoffer, 1963). Presentan actividad biológica antioxidante, astringente, antidiarreico, antidisentérico, hipoglucemiante, hepatoprotector, antibacterial, antidiabético, antialérgico, cordial, antiinflamatorio y anticancerígeno (Hurrell et al., 2010). Las plantas son cultivadas para sombra en los patios (Keller, 2008b).

5. "Algarrobo" (esp). Prosopis alba Griseb., P. chilensis (Molina) Stuntz, P. affinis Spreng., P. nigra Hieron., P. flexuosa DC. FABACEAE.

"(...) es arbol muy conocido por todas estas Provincias, aunque en estas Misiones no hay, sino tal cual que algunos Padres sembraron sus semillas en las huertas, trahidas de Santiago del Estero, á donde todos los montes los mas de los arboles son de su especie: son cuatro las diferencias que hay, es á saver: dos blancos masculinos y femeninos, y dos negros de distintas señales, porque el blanco es mayor asi macho como hembra. El macho echa las algarrobas de una, y pocas largas de una cuarta. La hembra las echa á modo de racimos en un pie 9 ó 10, unas veces menos otras mas. La negra es mas fructifera asi macho como hembra, sus frutos redondos, como aquellos de los judijuelos, o frisoles, es menos gustoso, y mas calido su fruto, y de menos estima para el uso de alojas y bebidas, y asi es poco estimado para comida, pues á donde la cojen para sustento y guardar para entre año en lugar de grano no hacen mucho caso de ella (...)" (p. 103-105).

Los caracteres que emplea Montenegro para identificar los algarrobos están exclusivamente relacionados a los frutos: el color, la longitud 
y la agregación de los frutos. Con los dos primeros caracteres los diferencia en dos grupos, "blancos" (frutos blancos, de mayor longitud) y "negros" (frutos negros, de menor longitud), mientras que con la cantidad de frutos por racimo los diferencia en "macho" (frutos solitarios) y "hembra" (frutos en racimos). De esta manera, las combinaciones presentadas por el autor son las siguientes:

A. "Algarrobo blanco hembra", seguramente $P$. alba, árboles hasta de $18 \mathrm{~m}$ de alto y frutos amarillentos hasta de $25 \mathrm{~cm}$ de longitud, en racimos.

B. "Algarrobo blanco macho", P. chilensis, árboles de 3 a $18 \mathrm{~m}$ de altura y frutos amarillentos, hasta de $20 \mathrm{~cm}$ de longitud, solitarios.

C. "Algarrobo negro hembra", P. flexuosa, de 3-8 $\mathrm{m}$ de alto, chaucha carnosa, violácea, de 5-20 cm de largo por 1-1,5 cm de ancho, muy dulce; y P. affinis, de 2-10 m de alto, chaucha carnosa de $8-15 \mathrm{~cm}$ de largo por 1-2 cm de ancho, amarillenta con estrías violáceas; sabor amargo y astringente.

D. "Algarrobo negro macho", P. nigra, de 3-8 $\mathrm{m}$ de altura, chaucha carnosa, amarilla con estrías violáceas, muy dulce.

Según el autor, es más eficaz como antidiarreico el "algarrobo negro", tanto "macho" como "hembra". También ha dicho que se utiliza el fruto verde como ungüento en emplastos para quebraduras y que los frutos maduros son empleados para hacer aloja, la cual, tomada con moderación, deshace las piedras de la vejiga y cura la hidropesía. Los otros jesuitas destacan esta planta, que los guaraníes llaman "ibope" y los abipones "roàk", como alimenticia, para elaborar bebidas alcohólicas, como forraje de engorde para el ganado, y como medicinal para el dolor de ojos (Lozano, 1941; Dobrizhoffer, 1967).

Se amplía el repertorio de especies del trabajo de Perkins de Piacentino (2007) a las cuatro presentadas en este trabajo.

6. "Flor de la Pasión", "granadilla", "granadillas de la pasión", "granadilla amarilla" (esp). "Mburucuyá", "mburucuyá amarillo", "mburucuyá colorado" (guar). Varias especies del género Passiflora L., entre estas: P. alata Curtis, $P$. amethystina J. C. Mikan (?), $P$. cincinnata Mast., P. caerulea L., P. edulis
Sims. (?), P. elegans Mast., P. morifolia Mast., P. suberosa L. y P. umbilicata (Griseb.) Harms. PASSIFLORACEAE (Fig. 3b, e).

“(...) hay en este género cuatro especies, que son: amarillo, encarnada, morada y negra, porque asi se vuelven su fruto para sazonar, $y$ todas cuatro se conocen por sus ojas y bastagos (...). Sus ojas son trinitarias, su fruto en lo interno partido en el nacimiento en tres ternos $y$ en sustancia unido perfectisisimamente (sic) (...) que habiendo en su esfera interior seis ternos en todo iguales, los tres sean los que fructifican, y los otros tres esten vacios blancos, lisos y muy tersos, los cuales tiene su raya en medio muy proporcionadamente (...). Su flor contiene casi los misterios mas sobresalientes de la Pasion de Cristo (...). Pues que diré de lo agradable de su fruto que siendo agridulce es tan aromatico, que recrea los sentidos humanos, y sirve de sustento y medicina (...). [Crece] con grande abundancia por los bosques, arroyos, Chacaras de Indios, y huertas de los Pueblos, con admirable providencia, (...) trepase muy alto á veces sus sarmientos ó bastagos, hasta traparse á las copas de muy altos arboles, los cuales esparcidos en lo alto de ellos echan sus flores y frutos, lo cual comen hombres, monos y pajaros de donse se multiplica con abundancia" ( $\mathrm{p}$. 106-107).

El autor continúa con la "granadilla amarilla" o "mburucuyá amarillo": "Aunque en el capitulo antecedente dejo dicho que se hallan cuatro diversas especies de Mburucuyas, ó Granadillas de la Pasion, esto se hade entender las cuatro que aqui doy por estampa de sus ojas, (...) hay otras seis espúreas especies de Mburucuyas, unos tan pequeños como las frutillas del Guabiyú mirí, y su flor no se estiende á mas ambito y circuito que el de un medio real de plata (ca. 14-15 mm de diámetro) (...). De las dos primeras dejo dicha ya sus virtudes: ahora pretendo decir algo de las otras dos silvestres, que se hallan á menudo por matorrales de cerranias, y á las orillas de los arroyos, rios y montes, y á veces por las huertas de arboledas (...). Es pues el Mburucuyá amarillo silvestre un Isipó tan grueso como la muñeca de un hombre, el cual se trepa en las copas de los mas elevados arboles, (...) sus hojas [son] muy espesas y pequenas, casi nada endidas; 
pero de tres globos algo rotundos sin puntas ni comparticiones, muy densas, delgadas y tersas: su flor es de color jaspeado de morado y blanco, toda conferencia de su corona de espinas de suabe y muy aromatico olor, el cual ninguna de las otras posehe tal dote (...). El Mburucuyá colorado es su fruto algo largo á modo de huevo; pero igual sin puntas, son muy frecuentes á las orillas de los arroyos, y por los carcabuesales, á la orillas de los bosques: es de ordinario muy delgado su bastago, y se extiende muy corto, como cinco ó seis varas $(4,2$ a 5,04 m) á lo más; sus flores son moradas, y la pulpa de sus granos encarnada; hay algunos de esta especie que hacen la corteza, ó cascara de su fruto amarilla, y asi mismo larga; pero en lo interno encarnada la sustancia de su fruto, las cual es incipida y algo ingrata al gusto, sin aquel agridulce de las tres ya dichas, por lo cual son muy poco apetecidas de los Indios, solo son sustento de pajaros y hormigas monteses (...). Las raices de las otras dichas todas ellas son blancas de corteza: pero esta cuarta especie las hase algo cetrinas, tirante su corteza interno al color encarnado, ó cárdeno oscuro (...)" (p. 109-113).

No hay dudas de que el autor se refiere al género Passiflora. Sin embargo, para denotar su variabilidad sólo se refiere a la coloración del fruto maduro, sin brindar otra información que permita diferenciar la diversidad intragenérica presente en el Noreste argentino. Empleando el trabajo de Deginani (2001) se concluye que la variedad "encarnada" (roja) puede tratarse de $P$. cincinnata, la única de las especies citadas de frutos con exocarpo rojizo-amarillento a la madurez. La variedad "negra" puede tratarse de $P$. morifolia o de una variedad de P. edulis, ambas con frutos con exocarpos violáceos a negruzcos cuando maduros. Con respecto al "mburucuyá morado" también pueden ser posibles: $P$. amethystina, $P$. edulis y $P$. morifolia. Otras dos especies, $P$. misera Kunth y $P$. suberosa, poseen también frutos morados pero estos son muy pequeños, con diámetros entre 5 y $16 \mathrm{~mm}$. La variedad "amarilla" es la que presenta mayor variabilidad. Deginani (2001) menciona 10 especies con frutos de color amarillo a amarillo-anaranjado a la madurez. Con respecto a las especies de flores y frutos pequeños puede tratarse de $P$. suberosa, con diámetros de 6 a $20 \mathrm{~mm}$ (flores) y 5 a $13 \mathrm{~mm}$ (frutos). Hay otras especies con flores pequeñas: $P$. umbilicata y $P$. morifolia; sin embargo, el rango de diámetro varía entre 12 y $70 \mathrm{~mm}$, por lo cual son menos probables. La descripción del "mburucuya amarillo silvestre" de Montenegro coincide con la de $P$. alata, una enredadera hasta de $20 \mathrm{~m}$ de longitud, con tallos hasta de $10 \mathrm{~cm}$ de diámetro y hojas trilobadas, con lóbulos semi-orbiculares poco a muy marcados, y radii blancos con franjas transversales violeta y lila de diferentes tamaños. También, considerando a la variedad "amarilla", seguramente se trate de un complejo de especies conformada por $P$. coerulea L., P. edulis y P. elegans, entre otras.

Según Montenegro (p. 107-113) las "frutas del Mburucuyá comidas con moderacion hasta diez de ellas abren las vias, refrezcando el estomago, higado y corazon, con un modo muy suave y cordeal" (usos digestivo y cordial). También “(...) socorre á los de piedra de riñones y vejiga deshaciendola, y minorando el humor de que se forma (...)" y "(...) es único remedio en quebrar y deshacer la piedra (...)" (usos renal y para deshacer cálculos renales). Con respecto a la flor, el jesuita nos dice que puede usarse como sustituto del lúpulo. La raíz es: “(...) eficaz en destruir el mal frances, (...) calentar y confortar los miembros principales (...) que son el celebro: nerbios, estomago, higado, bazo, vejiga, intestinos gruesos, y tendones" (usos como antisifílico y tónico general). Además, cita las otras variedades como cicatrizante (polvo de la corteza) y contra las hemorragias internas y disenterías (raíces). Es otra de las plantas mencionadas por la mayoría de los jesuitas, que los fascinó tempranamente debido a que en sus flores interpretaban los elementos de la Pasión de Cristo (crucifixión), y que recomendaban también como frutal y en la elaboración de confituras (Dobrizhoffer, 1967; Lozano, 1941; Paucke, 1944; Sepp, 1971).

Las diversas especies del género Passiflora antes mencionadas poseen frutos comestibles que en la actualidad pueden consumirse frescos o en diversas preparaciones como jugos, mousses, jaleas, dulces, mermeladas, helados, bebidas, conservas, en ensaladas, cocidos como acompañamiento de carnes, entre otros usos (Hurrell et al., 2010; Martínez-Crovetto, 
2012; Kinupp \& Lorenzi, 2014). Entre los usos medicinales de las diversas especies de Passiflora se encuentran los siguientes: antiespasmódico, analgésico, febrífugo, sedante, ansiolítico, cordial, hipotensor, vermífugo (Hurrell et al., 2010). Poseen acción neuroléptica como tranquilizante, sedativo, para el dolor de cabeza, entre otras. Algunas especies poseen crisina, un flavonoide activo con propiedades tranquilizantes y miorrelajante (semejante a los benzodiazepínicos); también se han encontrado flavonoides libres y glicosilados como la passiflorina (Lorenzi \& Abreu Matos, 2002).

7. "Piña" (esp). "Caraguatá" (guar). Ananas comosus (L.) Merr. y Bromelia balansae Mez. BROMELIACEAE.

“(...) especie de Cardo salvaje, que se halla en las orillas de los montes, has de él dos especies, la primera es ésta que aqui dejo estampada: la segunda es muy semejante á esta en las ojas y tallos; pero no en el fruto, porque lo hecha á modo de racimo en la punta y remate de la vara, la cual crece mas alta, y sin ojas; sus granos maduros son del tamaño de nueces amarillos, y algo aromaticos, y algo ingratos al estomago, aunque los Indios lo comen en tiempo de hambre. (...) echa en contorno de su principio varias plantas nuebas del largor de un jeme, que la rodean en redondo, y en la punta de la piña una sola planta muy poblada de ojas (...)" (p. 113-114).

Con la primera especie se refiere seguramente a Ananas comosus debido a la presencia de la roseta apical de hojas por encima del sorosio (infrutescencia), al mismo tiempo descartando a Ananas sagenaria (Arruda) Schult. \& Schult. f. [=Pseudananas sagenarius (Arruda) Camargo] por la ausencia del mismo. La segunda especie se refiere a Bromelia balansae, debido a la descripción de los frutos ("racimos" que, en realidad, son espigas) amarillos, del tamaño de las nueces, refiriéndose a los frutos de Juglans regia $\mathrm{L}$.

El autor recomienda las infrutescencias de A. comosus junto a otras plantas, en infusión de vino o en jarabe, para "quebrar y deshacer las piedras de riñones (...) y vejiga (...) y limpiar las llagas de riñones y vejiga". También la recomienda para "fiebres ardientes", como diurético y estomacal. Estas plantas son también apreciadas por otros jesuitas quienes consideraban a $A$. comosus como frutal y para conservas con azúcar (Paucke, 1944; Dobrizhoffer, 1967), y a B. balansae como planta textil para elaborar hamacas, ropas, hilos para pescar y costura (Gilii \& Xuarez, 1792; Paucke, 1944; Dobrizhoffer, 1967).

La infrutescencia de A. comosus es hoy mundialmente empleada como fruta y en la elaboración de jugos, mermeladas y glaseados. La enzima bromelina, presente en el jugo, es empleada para tiernizar carnes y elaborar medicamentos. Su jugo es usado como remedio digestivo, emoliente, diurético, antiséptico y antitumoral; mientras que sus hojas son purgantes, emenagogas y vermífugas (Hurrell et al., 2010). Entre los Mbya guarani de Misiones las infrutescencias de $B$. balansae son consumidas cocidas en agua para combatir los vermes intestinales, mientras que la decocción del rizoma se recomienda para el dolor de cintura. Con las fibras se hacen sogas (Keller, 2008b; Martínez-Crovetto, 2012).

8. "Mamón” o "mamones" (esp). "Pinó guazú" (guar). Carica papaya L. CARICACEAE.

“(...) hay masculino y femenino, (...) el femenino es muy semejante á él (se refiere al masculino) en tronco ojas y fruto, solo el ser menor en todas estas cosas: crece el fruto del macho como un melon mediano, asi mismo amarillo al sazonar, y mas blando que el melón despues de sazonado: todo lo interior de su sustancia entreverado de ciertas semillas casi redondas, menores que alberjas, con ciertas puntillas claveteadas, de sabor algo agudo y picante (...). Su arbol todo es esponjoso y fistuloso, de suerte, que de una puñalada con un belduque se atraviesa de banda sin resistencia, asi como el de los platanos, echando de su herida copia de agua viscosa." (p. 242).

Se trata de Carica papaya. En este caso, el "masculino" y el "femenino" corresponden a la misma especie dado que ésta es dioica. Los pies femeninos poseen racimos cortos paucifloros, con flores pistiladas; mientras que los pies masculinos están caracterizados por racimos mayores a $20 \mathrm{~cm}$, plurifloros, con flores estaminadas. Sin embargo, de acuerdo a las condiciones ambientales, pueden aparecer 
flores hermafroditas que se fecunden para conformar frutos largamente pedunculados (León, 1987). Montenegro indica sus semillas como remedio laxante y febrífugo, y sus frutos los recomienda para la elaboración de conservas. Otros jesuitas mencionan esta especie como frutal y también para cocinar, además de sus propiedades estomacales (Gilii \& Xuarez, 1792; Dobrizhoffer, 1967).

Actualmente sus frutos son consumidos frescos, en conservas, mermeladas, helados, jugos, confitados y glaseados. Las hojas, frutos y semillas se emplean para trastornos gastrointestinales, como vulnerario, vermífugo y antioxidante (Hurrell et al., 2010).

\section{9. "Plátanos" (esp). "Pacobá" (guar).} Musa $\times$ paradisiaca L. MUSACEAE (Fig. 1c, d).

"Solas dos diferencias de Platanos hallo en estas tierras muy parecidas las dos, excepto, que el fruto es algo diverso, asi en grandor como en sabor, y olor, porque hay los platanos largos y delgados de grandes racimos, que apenas pueden sustentarlo por algún tiempo: en una mano que lo he visto de arroba y media (ca. $17 \mathrm{~kg}$ ) de peso su fruto ó Pacobá, casi de un jeme (ca. $20 \mathrm{~cm}$ ) de largo, algo correoso de sustancia, y asi mismo mas indigestas, pesadas al estómago, y mas frias que las que dicen de Sta. Catalina, q.e son las que aqui doy pintadas (...). Crece de ordinario de dos estados de alto, del grosor de un muslo de hombre robusto, pone dos ó tres años en dár su fruto, y al primero que dá se pudre dicho arbol hasta la raiz, saliendo otro en su lugar, y á veces dos y tres, por lo cual se llega espesar las plantas mucho, y entonces dán poco fruto. Sus ojas son de á vara y cuárta (1,06 m), y de vara y media $(1,27 \mathrm{~m})$ de largo, y casi de media de ancho (42 cm), muy hermosas y tersas á la vista, y de notable virtud en refrescar á los que se ponen á su sombra. Sus flores son entre amarilla y blanca, la cual sale en la cabeza del fruto, (...) el cual es del largor de un dedo y grueso: de suerte, que llenan algunos la mano, muy suave en sustancia, y olor, no tan (...) indigesto, como las arriba dichas, que por su pobreza las llaman artabellacos (refiriéndose a Arbutus unedo L.)" (p. 244).

Se trata de las dos variedades comúnmente conocidas de Musa $\times$ paradisiaca, el "plátano" y la "banana". Las descripciones del autor son coincidentes y permiten diferenciar las dos variedades debido al tamaño de los "cachos", a la cantidad de frutos por racimo, al tamaño de los frutos, y la digestibilidad del endocarpo, de acuerdo a la presencia de almidón (en los "plátanos" o "pacobá") y de azúcares ("pacobá de Santa Catalina").

El autor indica los frutos del "plátano" como tónicos para "abrir el apetito", como febrífugos, laxantes leves y para impedir la embriaguez. Los recomienda en las insolaciones, tanto al interior como al exterior. Al exterior también los recomienda junto a aceite rosado (?) para miembros hinchados y para conciliar el sueño, también junto a cenizas de sarmientos (Vitis vinifera L.), manteca o tuétanos de ternera, para curar llagas. Otros jesuitas indican esta especie también como frutal, pero agregando las mismas propiedades medicinales (Gilii \& Xuarez, 1792; Dobrizhoffer, 1963; Sainz et al., 1989).

Actualmente, plátanos y bananos son cultivados y empleados como fruta fresca, cocida, desecada, en postres, salsa, tartas, helados, licuados y bebidas fermentadas. Las hojas son empleadas para envolver comidas, para techar casas y como fuente de fibras vegetales. Las propiedades medicinales incluyen su uso como vulnerario, hepático, antidisentérico, antiasmático y antitusivo (flores); para trastornos digestivos e intestinales (raíces); para picaduras de insectos, hemorroides, fiebres y hemorragias (savia); como remedio antidiarreico, antioxidante e hipotensor (frutos) (Hurrell et al., 2010).

\section{0. "Guembé" (guar). Philodendron} bipinnatifidum Schott ex Endl. ARACEAE.

"El Guembé (...) es dotado de un verde claro, tersas sus ojas, muy densas en sustancia, de notables hendiduras, de ancho de á tres cuartas, y algunas de á vara $(0,84 \mathrm{~cm})$, proporcionalmente largas, compartidas cada una en tres puntas ó globos, y de pie de cada oja sale como una bayna larga de á cuarta, y muchas de á tercia $(30 \mathrm{~cm})$ : dentro de dicha vaina tiene un modo de espiga, ó marlo, en el cual están acidos ciertos granillos muy menudos de que se viste dicha espiga interna, toda ella claveteada de alto abajo: esta bayna á los quince dias de producida se abre á modo de lanterna, dejando cerrado el extremo, 
sacando al Sol y sereno su fruto, mostrando todo lo interior un blanco terso como la plata (...). La tercera parte de la espiga, en la parte mas baja, que es la que sazona y dá el fruto, el cual es dulce: su armazón á modo de piña compuesta de granos grandes, como aquellos del maiz blanco; pero más largos, compuesto cada uno de ellos de muchos muy menudos (...). Una de estas plantas se hallan en tierra; pero lo ordinario se hallan pendientes de los árboles en sus troncos, á donde las caliente el Sol, tirando sus raices á tierra para sustentarse (...)" (p. 253-255).

De acuerdo a la descripción ofrecida por Montenegro no caben dudas de que se trata de Philodendron bipinnatifidum, que en Misiones puede diferenciarse de $P$. undulatum Engl. (también presente en la zona de las antiguas Jesuíticas) por la mayor profundidad de las hendiduras de sus hojas, entre otros caracteres.

El autor cita múltiples aplicaciones para esta planta epífita: medicinales, textiles y alimentarias. En cuanto a sus propiedades medicinales ha sido empleada para el tratamiento del reuma, como laxante (para "los humores frios reumaticos y viscosos de las vías por donde pasa, dejando descargado el estómago y vientre"), como antídoto contra animales venenosos ("socorre a los temblores paroximales por causa fría, o humedad, y a los que han tomado mantenimientos muy fríos $o$ venenosos"), como antiparasitario ("remedio para matar lombrices y gusanos"); y al exterior para el tratamiento de lamparones como también las llagas de los mismos. Como textil, se emplea para tejidos de cestos, cedazos, esteras y sogas para marinerías y ataduras fuertes. Dobrizhoffer (1967) también menciona esta planta como frutal y textil de reputación conocida. En la actualidad se cultiva como ornamental, las infrutescencias son comestibles. De la corteza de las raíces se obtienen fibras para uso textil, empleadas en la confección de cestos, herramientas e instrumentos. El jugo de las hojas se emplea en medicina popular para cauterizar heridas, úlceras y contra el reumatismos semillas tienen propiedades vermífugas y las hojas trituradas se usan como insecticida (Jankowski et al., 2000; Keller, 2008b).

11. "Guabirá" (guar). Campomanesia aurea O. Berg, C. guabiroba (DC.) Kiaersk.,
C. guazumifolia (Cambess.) O. Berg y $C$. xanthocarpa O. Berg. MYRTACEAE.

"Cuatro diversas especies de Guabirás se hallan por esta tierras, es á saver: dos arboles grandes, que cada uno de ellos son diversos en ojas, fruto y cortezas, el uno mayor y el otro menor: el uno claro de color sus ojas, y el otro verde oscuras y mayores que las del blanco. Las otras dos especies son chiquitas aparragadas á tierras sus bastagos, aunque en el Paraná he visto otra $5^{a}$ especie muy semejante á esta que doy por estampa; pero de vara $(0,84 \mathrm{~cm})$ de alto sus varas, y algunas más; pero en el sabor $y$ partes muy semejantes, y asi mismo en la flor, ojas y fruto: tuvelo por el mayor de esta cuarta especie, que es el mejor en medicina, y sabor de su frutilla: nace en lomerias de Cerranias, $a ́$ donde hay cascajales, y piedras debajo: su flor es blanca, y su raiz gruesa asi como un puño, $y$ algunas redondas, otras largas, muy macizas y pesadas, las cuales estan cubiertas de una corteza muy gruesa, y de sustancia encarnada, muy astringente y fria al gusto, (...) su fruto casi lo mismo, (...) tienen de ordinario cada una tres pepitas dentro, cubiertas de sustancia viscosa. La frutilla de los dos primeros son á modo de perillas cermeñas algo menores, aunque tal cual es de su grosor y tamaño; pero con cierto mal olor en la piel, tirante al de las chinches campestres, á causa de su corteza, (...) que al comer enciende algun tanto la lengua y paladar, asi como el ajimollar [posiblemente se refiera al fruto de alguna especies de Schinus], que no pica mucho (...)" (p. 258-260).

La característica morfológicas expuestas por el jesuita Montenegro coinciden claramente con las de especies del género Campomanesia (flores blancas, fruto similar en forma a las peras cermeñas, olor resinoso característico y gusto levemente picante), especialmente $C$. xanthocarpa, C. guazumifolia, C. guabiroba y C. aurea, sin embargo, no se puede descartar que se trate de otros géneros subtropicales pertenecientes a la familia Myrtaceae. Las dos especies de "arboles grandes" a que se refiere el autor pueden tratarse de C. xanthocarpa y C. guazumifolia, hasta de 15 y $7 \mathrm{~m}$ de altura, respectivamente; mientras que una de las especies "chiquitas aparragadas á tierras sus bastagos" puede tratarse de C. aurea, subarbusto hasta de $1 \mathrm{~m}$ de altura. 
Montenegro menciona este frutal como odontálgico, antidisentérico y antidiarreico, y también para curar llagas y heridas. Dobrizhoffer (1963) menciona estas plantas como frutales, para hacer bebidas y aprecia sus maderas aptas para tornear. MartínezCrovetto (2012) menciona tres especies: $C$. aurea, C. guazumifolia y C. xanthocarpa, empleadas como frutal entre los Mbya guaraní de Misiones. Las dos últimas son empleadas como estomacales y contra vermes intestinales. C. guazumifolia, además, es empleada para curar la sordera y C. xanthocarpa como antiemético en niños. Actualmente, su fruta es consumida fresca y con su pulpa se preparan jugos, helados, bebidas, pulpa concentrada y congelada y otros derivados (Kinupp \& Lorenzi, 2014). Las plantas son cultivadas para sombra en los patios (Keller, 2008b).

12. "Tamarindos" (esp), "Ibáhai” (guar). Tamarindus indica L. y posiblemente a Hexachlamys edulis (O. Berg) Kausel \& D. Legrand. FABACEAE y MYRTACEAE, respectivamente.

“(...) es de muy pequeña estatura, á modo del de las jujubas, azufaifaz (Ziziphus jujuba Mill.), aunque algo menores: sus hojas es de naturaleza silvestre, asi como las endrinas (Prunus spinosa L.) de España: hállanse de él dos especies, el uno mas crecido de tronco, que es el masculino, el cual en fruto y ojas es mas diminuto que la femenina, (...) los que llaman Tamarindos reales, no se los haiga por estas partes, hasta la Ciudad de Santiago de Chile, que dicen los tienen yá domesticos, y los crian en los huertos, y por ser estas tierras del Paraná capaces de ellos me pareció poner sus estampas (...). Nacen estos arboles en abundancia á modo de matorrales ó montecillos, á donde hay minas de oro debajo (...), como en el Potosi, Perú, y Cuzco (...). Echa su fruto dentro de baynas (legumbres) á modo de las [del] maní (...); pero mayores y más gruesas, tan agri[a]s tirante algun tanto al sabor acedo (...)" (p. 272-273).

Sin dudas se trata de Tamarindus indica, especie de origen asiático introducida tempranamente. Sin embargo, destaca y describe dos especies que podrían tratarse de dos variedades de esta. La primera, "los tamarindos reales", puede tratarse de una variedad domesticada, mientras que la segunda, "los tamarindos bastardos", de una variedad arvense o ruderal. Respecto a esto, analizando la imagen de la página 275 , se puede destacar que los frutos no parecen legumbres, sino bayas carnosas uniseminadas. Este indicio, sumado al nombre guaraní que porta: “ibáhai”, podría indicarnos que el jesuita se puede estar refiriendo a Hexachlamys edulis. Por otra parte, no hay una descripción de los tamarindos bastardos, por lo cual esta identificación tentativa se sostiene por la semejanza entre los follajes de ambas especies, la ilustración del libro y el nombre guaraní.

En términos generales, las propiedades citadas por Montenegro son las siguientes: purgante, tónico y para quitar la sed en fiebres. Otros jesuitas la indican como refrescante y frutal (Dobrizhoffer, 1967; Sainz et al., 1989).

Actualmente es empleado como ornamental, maderable y frutal. Las variedades ácidas son empleadas como condimentos en salsas, curry y conservas; mientras que las variedades dulces se emplean para consumo fresco, aperitivos, jarabes, dulces, conservas, confituras y helados. Son empleados por sus propiedades antioxidantes, antimicrobianos, inmunomoduladoras $\mathrm{y}$ antiateroscleróticas (Hurrell et al., 2010).

13. "Árbol del Anime” (esp). "Yataiba"(guar). Hymenaea courbaril L. FABACEAE.

"Son dos especies muy parecidos en todo, menos en el color de la ojas, que el uno las hace mas blanquecinas, y algún tanto mas delgadas, que pienso ser la hembra, y el mas oscuro de ojas el macho. Es arbol alto y muy coposo, con muchas y muy compartidas ramas: su corteza del tronco y ramas muy gruesas, es algo aspera y como sarnosa, de color claro ceniciento: la de las ramas delgadas tersa, liza y verdosa: sus ojas de dos en dos, y siempre en las puntas de las ramas mas anchas de los lados de afuera, que los de adentro, á donde se juntan, esto es de la comparticion que hace la vena ó nervio, que la parte p.r (sic) medio: su flor es cierta piñuela puntiaguda y tierna, á modo de aquellas vaynitas de las judias ofrisoles cuando empiezan á crecer: las cuales poco á poco bán creciendo y ensanchando, como a dos dedos de ancho, ó dos y medio, de largo del dedo pulgar, $y$ al querer sazonar se pone aquella vayna dura y fuerte, con cierta sustancia, tirante al 
color encarnado claro, y en medio tres ó dos pepitas relucientes, de color castaño claro, á modo de aquellos de los Tamarindos, ó Caña fistola: cuando verde es de sabor amargo y astringente; pero al sazonar se vuelve de sabor de arina algo dulce, de suerte que es muy buen sustento á falta de pan, ó de maiz: echa de si por primavera y sin ser herido su goma, por ciertos poros á modo de verrugas, ó tolondrones, que él de suyo abre el olorosos anime, el cual viene en abundancia cayendo por el tronco (...). [Esta goma] (...) quemada despide de si un olor muy suave, y grato al celebro, corazon y ventriculo (...)" (p. 280-281).

Se trata de Hymenaea courbaril, también llamado "courbaril", "yataiba", "guapinol", "algarrobo". Es un árbol de América tropical y subtropical. Las descripciones del autor respecto al porte (árbol robusto), de las hojas (bifoliadas), la corteza, las ramas, las inflorescencias (racimos terminales cortos), y el fruto (legumbre indehiscente de color castaño oscuro) coinciden con las características de este árbol. Su fruto es una legumbre que madura pasando del color verdoso hasta el moreno oscuro. Posee una pulpa amarillenta comestible con la que se pueden hacer diversas preparaciones culinarias. Las dos especies que menciona pueden ser referencias a distintas variedades de la misma especie.

Montenegro indica que su perfume o sahumado es útil para curar y quitar el dolor de cabeza. También lo es su polvo amasado con aguardiente y colocado en las sienes. Lo menciona, además como sudorífico, junto a otras plantas (copal e incienso), y en el tratamiento de reumatismos. Esta planta no ha podido ser determinada en otros escritos jesuíticos.

Actualmente, su corteza es ampliamente utilizada en la Amazonía por sus propiedades medicinales, en especial para problemas respiratorios y urinarios. El té de la corteza es popularmente usado como bebida: se ingiere con leche, como sustituto del café. Con la harina se hacen panes, bollos, budines, bebidas en general, inclusive fermentadas y alcohólicas, cremas y dulces diversos. La harina es una buena fuente de proteína. Se cultiva como ornamental en Brasil y su resina es empleada en inciensos y barnices (Lorenzi \& Abreu Matos, 2002; Kinupp \& Lorenzi, 2014).

\section{Conclusiones}

La identificación botánica de especies vegetales en fuentes documentales históricas resulta de gran utilidad a la hora de ampliar, completar y verificar la información sobre dichas especies. Una buena cantidad de datos valiosos mencionados por los jesuitas y demás naturalistas en otras etapas históricas no podría ser aprovechada con plenitud sin la identificación botánica de las plantas aludidas. En este contexto, la información obtenida desde la etnobotánica histórica enriquece no sólo la perspectiva etnobotánica sino también al mejoramiento de las prácticas y utilizaciones actuales de las especies vegetales en consideración.

\section{Agradecimientos}

Queremos agradecer a CONICET, FONCyT y UNLP por los fondos otorgados para este trabajo. Al Laboratorio de Etnobotánica y Botánica Aplicada (LEBA), FCNyM, UNLP. A los revisores que criticaron de manera constructiva este trabajo, aportando sustancialmente al mismo.

\section{Bibliografía}

ANAGNOSTOU, S. 2005. Jesuits in Spanish America: Contributions to the explorations of the american Materia Medica. Pharmacy in History 47: 3-17.

ARENAS, P. 1997. Las fuentes actuales y del pasado para la etnobotánica del Gran Chaco. Monografías del Jardín Botánico de Córdoba 5: 17-25.

BARION ROMAGNOLO, M. \& M. CONCEIÇÃO DE SOUZA. 2004. Os generous Calycorectes O. Berg, Hexachlamys O. Berg, Myrcianthes O. Berg, Myrciaria O. Berg e Plinia L. (Myrtaceae) na planicie alagábel do alto rio Paraná, Brasil. Acta Botanica Brasilica 18: 613-627. https://oi.org/10.1590/S0102-33062004000300019

CADOGAN, L. 1992. Diccionario Mbya-guaraníCastellano. Asunción, Biblioteca Paraguaya de Antropología - Vol. XVII. 211 pp.

CAPPARELLI, A., N. HILGERT, A. LADIO, V. LEMA, V. LLANO, S. MOLARES, M. L. POCHETTINO \& P. STAMPELLA. 2011. Paisajes culturales de Argentina: pasado y presente desde la perspectiva etnobotánica y arqueobotánica. Revista ASADEP on line 2: 67-79. 
CARRERE, R. 2009. Un exótico frutal indígena llamado guabiyú. RAPAL, Red de Acción en Plaguicidas y sus Alternativas para América Latina, Uruguay. Disponible: http://www.rapaluruguay.org/organicos/ Guaviyu.pdf. (Consulta 12/05/18).

DECKMANN FLECK, E. C. 2013. The historiographical approach taken in the nineteenth and twentieth centuries to the work of Jesuit doctors and apothecaries in the La Plata region in the eighteenth century. Historia, Ciências, Saúde 21: 1-19.

DEGINANI, N. B. 2001. Las especies Argentinas del género Passiflora (Passifloraceae). Darwiniana 39: 43-129.

DOBRIZHOFFER, M. 1967 [1784]. Historia de los Abipones I. Resistencia, Facultad de Humanidades, Universidad Nacional del Nordeste. 568 pp.

GILII, F. L. \& G. XUAREZ. 1792. Osservazioni fitologiche sopra alcune piante esotiche introdotte in Roma fatte nell' anno 1788. Roma, Stamperia di Arcangelo Casaletti. 64 pp.

HILGERT, N. I., D. A. LAMBARÉ, N. D. VIGNALE, P. C. STAMPELLA \& M. L. POCHETTINO. 2014. ¿Especies naturalizadas o antropizadas? Apropiación local y la construcción de saberes sobre los frutales introducidos en época histórica en el norte de Argentina. Revista Biodiversidad Neotropical 4: 69-87. https://doi.org/10.18636/bioneotropical.v4i2.118

HURRELL, J. A., E. A. ULIBARRI, G. DELUCCHI \& M. L. POCHETTINO. 2010. Frutas frescas, secas y preservadas. Buenos Aires, Editorial L.O.L.A. $301 \mathrm{pp}$.

IBARRA, M. F. 2007. El Padre Pedro de Montenegro, 1700. Su tratamiento de herboristería para las afecciones mentales y sus referencias a la medicina hipocrático-galénica. XIV Jornadas de Investigación y Tercer Encuentro de Investigadores en Psicología del Mercosur. Disponible: https:// www.aacademica.org/000-073/71.pdf. (Consulta: 03/02/18).

JANKOWSKI, L., D. BAZZANO, A. SÁENZ; M. TOURN \& G. ROITMAN. 2008. Plantas trepadoras. Nativas y exóticas. En LAHITTE, H. B. \& J. A. HURRELL (eds.), Flora rioplatense V. Buenos Aires, Ed. L.O.L.A. 264 pp.

KELLER, H. A. 2008a. Etnobotánica de comunidades guaraníes de Misiones, Argentina; valoración de la vegetación como fuente de recursos. Tesis doctoral, Universidad Nacional del Nordeste, Argentina. 160 pp.

KELLER, H. A. 2008b. Las plantas usadas en la construcción y el acondicionamiento de las viviendas y templos guaraníes en Misiones, Argentina. Bonplandia 17: 65-81.

KELLER, H. A., A. PIRONDO \& P. C. STAMPELLA. 2018. El cultivo del ricino y el amba'y en comunidades guaraníes del nordeste argentino, aproximación etnobotánica de su historia y cosmología. Bonplandia 27: $23-30$. https://doi.org/10.30972/bon.2712983

KINUPP, V. \& H. LORENZI. 2014. Plantas alimentícias não convencionais (PANC) no Brasil. Guia de identificação, aspectos nutricionais e receitas ilustradas. São Paulo, Instituto Plantarum de Estudos da Flora Ltda. 768 pp.

LANDRUM, L. R. \& M. L. KAWASAKI. 1997. The genera of Myrtaceae in Brazil: an illustrated synoptic treatment and identification keys. Brittonia 49: 508536. https://doi.org/10.2307/2807742

LEÓN, J. 1987. Botánica de los cultivos tropicales. Costa Rica, Instituto Interamericano de Cooperación para la Agricultura. $445 \mathrm{pp}$.

LORENZI, H. \& F. J. ABREU MATOS. 2002. Plantas medicinales no Brasil. Nativas e exóticas. São Paulo, Instituto Plantarum de Estudos da Flora Ltda. 512 pp.

LOZANO, P. 1941 [1733]. Descripción corográfica del Gran Chaco Gualamba. Tucumán, Instituto de Antropología. 462 pp.

MARTÍNEZ, M., A. P. BARBEITO \& R. BOLAÑOS. La influencia jesuítica en la farmacología. Signos Universitarios 9: 51-57.

MARTÍNEZ-CROVETTO, R. N. 1981. Las plantas utilizadas en la medicina popular en el noroeste de Corrientes (República Argentina). Miscelánea 69: 1-139.

MARTÍNEZ-CROVETTO, R. N. 2012. Estudios etnobotánicos V. Nombres de plantas y su utilidad según los Mbya guaraní de Misiones, Argentina. Bonplandia 21: 109-133.

MONTENEGRO, P. 2009 [1710]. Materia Médica Misionera. Herbolario guaraní siglo XVII. Córdoba, Buena Vista Editores. 436 pp.

OCHOA, J. J. \& A. H. LADIO. 2011. Pasado y presente del uso de plantas silvestres con órganos de almacenamiento subterráneos comestibles en la Patagonia. Bonplandia 20: 265-284.

PAUCKE, F. 1944 [1749-1767]. Hacia allá y para acá (una estada entre los indios Mocobíes, 1749-1767), tomo III, segunda parte. Tucumán-Buenos Aires, Universidad Nacional de Tucumán e Institución cultural Argentino-Germana. 445 pp.

PERKINS DE PIACENTINO, A. M. 2007. Misiones Jesuíticas: drogas autóctonas americanas encontradas en la botica jesuítica de la ciudad de Santa María de Buenos Ayres. 38th International Congress for the History of Pharmacy, Sevilla. Disponible: https://idus.us.es/xmlui/bitstream/ handle/11441/39984/170.pdf; sequence $=1$. (Consulta: 14/01/18).

POLETTO, R. 2014. Uma trajetória por escrito: Pedro Montenegro SJ. e sua Materia Medica Misionera. Tesis doctoral, Universidad do Valle do Rio dos Sinos, Brasil. 218 pp.

RICCIARDI, A. I., N. E. CABALLERO \& C. CHIFA. 1996. Identificación botánica de plantas descriptas en "Materia Médica Misionera" usadas en accidentes ofídicos. Rojasiana 3: 239-245. 
RODRÍGUEZ BARBOZA, N. 1985. Pojhá ñaná. Recetario de plantas medicinales usadas en el Paraguay. $2^{\mathrm{a}}$ edición. Asunción, Editora Litocolor. 356 pp.

ROSSO, C. N. 2012. La etnobotánica de los grupos mocovíes de la reducción de San Javier, en el Gran Chaco, durante el siglo XVIII. Tesis doctoral, Universidad de Buenos Aires, CABA. 307 pp.

ROSSO, C. N. 2013. La etnobotánica histórica: el caso mocoví en la reducción de San Javier en el siglo XVIII. Etnobiología 11: 54-65.

ROTMAN, A. D. 1976a. Revisión del género Campomanesia en la Argentina (Myrtaceae). Darwiniana 20: 327-340.

ROTMAN, A. D. 1976b. Revisión del género Psidium en la Argentina (Myrtaceae). Darwiniana 20: 418-444.

ROTMAN, A. D. 2000. Flora Fanerogámica Argentina: 222. Myrtaceae, parte 1: Subfam. I. Leptospermidae, Subfam. II. Myrtoideae, parte 1, Subtribu I. Myrtinae. Buenos Aires, Proflora No 70 (CONICET). 23 pp.

SAINZ, H., H. SAINZ, F. SUÁREZ y M. VÁZQUEZ. 1989. José Sánchez Labrador y los naturalistas jesuitas del Río de la Plata. Madrid, Ministerio de Obras Públicas y Urbanismo. 334 pp.

SCHMEDA HIRSCHMANN, G. 1988. Ethnobotanical observations on Paraguayan Myrtaecae. I. Journal of Ethnopharmacology 22: 73-79. https://doi.org/10.1016/0378-8741(88)90232-2

SEPP, A. 1971 [1696]. Relación de viaje a las misiones jesuíticas. Tomo 1. Buenos Aires, EUDEBA. 245 pp.

STAMPELLA, P. C., D. A. LAMBARÉ, N. I. HILGERT \& M. L. POCHETTINO. 2013. What the iberic conquest bequeathed to us: the fruit trees introduced in argentine subtropic, their story and importance in present traditional medicine. Evidence-Based Complementary and Alternative Medicine 2013, ID 868394, 17 pages. https://doi.org/10.1155/2013/868394

STAMPELLA, P. C. 2015. Historia local de naranja amarga (Citrus $\times$ aurantium L., Rutaceae) del Viejo Mundo asilvestrada en el corredor de las antiguas Misiones Jesuíticas de la provincia de Misiones (Argentina). Caracterización desde una perspectiva interdisciplinaria. Tesis doctoral, Universidad Nacional de La Plata, Argentina. 230 pp.

STORNI, J. S. 1944. Hortus Guaranensis. Flora. Tucumán, Universidad Nacional de Tucumán. 268 pp.

THE PLANT LIST. 2013. A working list of all plant species. Disponible: http://www.theplantlist.org/. (Consulta 03/03/18).

TRINIDADE MEDEIROS, M. F. 2010a. Procedimientos para a análise documental na constituição da informação etnobiológica. En ALBUQUERQUE, U. P., R. F. PAIVA DE LUCENA \& L. V. FERNANDES CRUZ DA CUNHA (eds.), Métodos e técnicas na pesquisa etnobiológica e etnoecológica, pp. 421435. Recife, NUPEEA.

TRINIDADE MEDEIROS, M. F. 2010b. Historical ethnobotany: an approach through historical documents and their implications nowadays. En ALBUQUERQUE, U. P. \& N. HANAZAKI (eds.), Recent developments and case studies in ethnobotany, pp. 127-142. Recife, NUPEEA.

ZULOAGA, F., O. MORRONE \& M. J. BELGRANO (eds.). 2008. Catálogo de plantas vasculares del cono sur (Argentina, sur de Brasil, Chile, Paraguay y Uruguay). Disponible: http://www2.darwin.edu. ar/Proyectos/FloraArgentina/FA.asp. (Consulta $11 / 02 / 18)$. 